\title{
Práticas musicais do cotidiano na Iniciação Científica: diários de pesquisa em ambientes religiosos cristãos
}

Musical practices of everyday life in undergraduate research: research diaries in Christian religious environments

Ana Lúcia Louroi

Universidade Federal de Santa Maria

André Müller Reckii

Universidade Federal do Pampa

\begin{abstract}
Resumo Nesta comunicação relatamos uma pesquisa de Iniciação Científica, a partir da perspectiva da valorização dos conhecimentos cotidianos na formação de professores de música. Duas licenciandas e um bacharelando em música de cursos de uma universidade do sul do Brasil escreveram diários de pesquisa sobre sua atuação enquanto lideres de grupos musicais em igrejas evangélicas e um ministério de música católico, que foram analisados à luz de Zabalza (2004). Tomado o dilema principal: "Ser músico ou ministro de louvor", surgiram duas categorias, considerando-se os horizontes de significados (Souza, 2013) dos alunos e dos músicos estudados por eles: 1. Amar a Deus mais do que a música; 2. Amar o próximo mais do que a música. A partir das leituras aqui propostas, pretende-se contribuir para os debates sobre pesquisa (auto)biográfica, especialmente com diários de pesquisa, estudos sobre ambientes religiosos cristão e formação de professores, a partir da reflexão sobre vivências significativas em suas vidas.
\end{abstract}

Palavras-chave: cotidiano, aprendizado de pesquisa, ambientes religiosos, diários de pesquisa, formação de professores de música.

Abstract In this communication reported a studie of scientific research, from the perspective of recovery of everyday knowledge in music teacher training. Two graduates and a Bachelor's degree in music from University courses in southern Brazil wrote diaries of research on your performance as musical groups leaders in Evangelical churches and a Catholic music Ministry, that were analysed based on Zabalza (2004). The main dilemma: "be a musician or Minister of praise", there were two categories, considering the horizons of significance (Souza, 2013) of students and musicians studied for them: 1. Love God more than music; 2. Love the near more than music. From the readings proposed here to contribute to the discussions on autobiographical research, especially

Revista Digital do LAV - Santa Maria - vol. 10, n. 2, p. 200 - 212 - mai./ago. 2017 ISSN 1983 - 7348 http://dx.doi.org/10.5902/1983734827859 
research diaries, studies on Christian religious environments and teacher training, from the reflection on meaningful experiences in their lives.

Keywords: everyday, learning research, religious environments, classrooms, training diaries of music teachers.

\title{
1. Do cotidiano para a formação de professores de música
}

A valorização dos saberes advindos da vida cotidiana faz parte de uma perspectiva que considera as experiências pedagógicas prévias de alunos de cursos de formação inicial de professores. Tal valorização vai ao encontro do parecer CNE/CP 09/2001, quando este argumenta sobre a possibilidade de considerar os

\begin{abstract}
conhecimentos que esses alunos possuem, em função de suas experiências anteriores de vida cotidiana e escolar. A outra forma ocorre quando os alunos dos cursos de formação, por circunstâncias diversas, já têm experiência como professores e, portanto, já construíram conhecimentos profissionais na prática e, mesmo assim, estes conhecimentos acabam não sendo considerados/tematizados em seu processo de formação (BRASIL, 2001, p.19).
\end{abstract}

Dentro dos estudos sobre Educação Musical neste viés se destacam as abordagens sobre Cotidiano e Educação Musical, desenvolvidas pelo grupo liderado pela professora Jusamara Souza na UFRGS (SOUZA, 2000; 2016). No que se refere ao ensino superior ganha destaque o livro "Educação Musical, Cotidiano e Ensino Superior", organizado por Ana Lúcia Louro e Jusamara Souza, de 2013 (LOURO; SOUZA, 2013). Para a última autora, "de uma maneira geral as teorias do cotidiano analisam os processos de construção simbólica e as regras implícitas e explícitas no mundo da vida cotidiana privilegiando as relações intersubjetivas" (SOUZA, 2013, p.16). Em relação a pesquisas com esse enfoque, Souza (2013) destaca que uma de suas contribuições é

considerar a experiência pré-científica, pré-teórica, fora do campo das ciências estabelecidas. E a valorização da experiência vivida de mundo, do sensívelconcreto, torna-se importante porque a vida humana ocorre grande parte neste nível (SOUZA, 2013, p.17)

Neste contexto, surgem as experiências prévias de licenciandos em música em ambientes religiosos, já destacadas por alguns autores da educação musical (TRAVASSOS, 1999; MARQUES, 1999) e consideradas por teóricos da sociologia da Educação como relevantes para o campo em questão (SETTON, 2008). Nesta direção, diversos trabalhos têm sido apresentados em congressos (LORENZETTI, 2013; SOUZA;

Revista Digital do LAV - Santa Maria - vol. 10, n. 2, p. 200 - 212 - mai./ago. 2017 ISSN 1983 - 7348 http://dx.doi.org/10.5902/1983734827859 
LIMA, 2013; SOARES; KAISER, 2013; RECK; LOURO, 2013), escritos em revistas da área (RECK; LOURO; RAPÔSO, 2014), e propostos como pesquisas em nível de graduação (CATTELAN, 2012; NOGUEIRA, 2012; OLIVEIRA, 2016) e pós-graduação, com destaque para a dissertação de mestrado de Lorenzetti (2015). Nesta última, a autora aponta como músicos que atuam dentro da igreja católica da Arquidiocese de Porto Alegre/RS, por ela entrevistados, consideram a importância de uma aproximação entre a formação universitária e a sua atuação em diversos contextos, entre eles, os religiosos. Desta forma, a experiência em ambientes religiosos se configura como pré-teórica, anterior à formação profissional na universidade, e opção de atuação profissional, entre um leque amplo de outras possibilidades.

Nos dois casos, as teorias do cotidiano apontarão a possibilidade de um transbordamento da experiência vivida às instâncias de formação inicial e/ou continuada dos professores e músicos atuantes dentro de um mundo simbólico vivenciado de forma intersubjetiva. Tal processo, parafraseando Kraemer (2000), está inserido na relação das pessoas com a(s) música(s). Nesta direção, este último autor aponta que tais relações se tornam o objeto privilegiado das pesquisas em Educação Musical.

A presente pesquisa, vinculada ao grupo de pesquisas NarraMus ${ }^{1}$, busca partir das realidades cotidianas dos alunos de cursos superiores de música, enquanto pessoas que estão envolvidas com ambientes religiosos. Considera-se que este tipo de envolvimento não é incomum entre professores de música em formação. No entanto, ao escolher os ambientes religiosos, no caso cristão, se destaca um dos aspectos da vida cotidiana dos alunos. Outras análises poderiam versar sobre suas vivências musicais em família, bares, estúdios, bandas e outros ambientes do seu dia a dia.

A pesquisa foi intitulada "Músicos e professores de música em ambientes religiosos: transbordamentos entre o vivido e os currículos", e teve como objetivo geral analisar as gêneses dos horizontes de significados de experiências musicais e pedagógico-musicais de músicos e professores. E como objetivos específicos: a) Compreender os transbordamentos de experiências do mundo vivido para as formações iniciais e continuadas de músicos e professores; b) Pontuar as experiências musicais e pedagógico-musicais que se destacam nas narrativas como marcantes para a (auto)formação de músico e professores; c) Sublinhar a presença de dilemas nestas experiências; d) Problematizar as tensões e celebrações para as práticas musicais e pedagógico-musicais que são peculiares aos ambientes religiosos. Cabe destacar que embora os dados tenham sido produzidos por estudantes de graduação a partir de uma

\footnotetext{
${ }^{1}$ Grupo de pesquisa Cnpq, coordenado pela professora Dra Ana Lúcia Louro, e ligado ao Departamento de Música e ao Programa de Pós Graduação em Educação da Universidade Federal de Santa Maria.
} 
ação de Iniciação Científica a análise desse artigo foi feita por professores pesquisadores buscando problematizar os diários produzidos pelos acadêmicos.

\section{Aprendizagens cotidianas em ambientes religiosos}

Na educação musical, talvez seja possível situar o início de uma literatura sobre o assunto no trabalho de Torres (2004) que, ao entrevistar um grupo de alunas da pedagogia sobre a construção das suas identidades musicais a partir das memórias, reconheceu nas narrativas considerações importantes sobre o papel da religião nesse processo. Num recorte sobre o tema, a autora se surpreendeu "com a multiplicidade de fatos e lembranças musicais que emergiram juntamente com as práticas religiosas, compondo diferentes cenas e aspectos da religiosidade" (TORRES, 2004, p.64).

Embora ainda recente, o campo das pesquisas que trata das relações pedagógicomusicais em ambientes religiosos tem se nutrido de uma série de trabalhos a partir de diferentes enfoques: Zanandrea (2009), Louro et. al. (2011), Reck, Louro e Rapôso (2014), Nogueira (2012), Cattelan (2013), Reck; Louro (2013), Blazina (2013), Lorenzetti (2013, 2015), Souza; Lima (2013), Soares; Kaiser (2013), Novo (2015) dentre outros. Além da emergência de tais pesquisas, podemos compartilhar um crescente interesse no tema a partir de encontros e fóruns realizados. Por exemplo, durante os dois últimos congressos nacionais da Associação Brasileira de Educação Musical (ABEM), realizados em Pirenópolis/GO (2013) e Natal/RN (2015) respectivamente, os grupos de trabalhos que envolviam as discussões sobre educação musical em contextos sociomusicais (não-formais e informais), foram palco da troca de ideias teórico-metodológicas e da percepção de um envolvimento na área, por parte de interessados em pensar a educação musical e suas relações com a religião.

Também no cenário internacional, a temática parece conhecer um novo status de importância, no que se refere aos espaços dedicados para suas discussões. Destaca-se o Grupo de Trabalho sobre Música e Espiritualidade apresentado durante o congresso da ISME (Internacional Society of Music Education), realizado em Porto Alegre/RS (2014), assim como os trabalhos e conferências organizadas pela SAME (Spirituality And Music Education), que em 2015 realizou seu $3^{\circ}$ encontro, na África do Sul. No que tange a Educação Musical inglesa, Lucy Green e Susan O'Neill² identificam alguns desafios para pensar o ensino curricular de música levando em conta a diversidades dos grupos sociais, dentre eles, os grupos étnicos/religiosos. Segundo as autoras, ainda são poucas as

\footnotetext{
${ }^{2}$ Em artigo intitulado Relavamiento de la educacion musical en el Reino Unido, produzido pelo grupo de Revisão da Educação Musical da BERA (British Educational Research Association) e publicado na Revista Psychology of Music em espanhol vol 32 número 3, em Julho de 2004, p.4-45.
} 
pesquisas que examinaram as relações desses diferentes grupos com a educação musical formal no Reino Unido, notando, por exemplo, que algumas famílias muçulmanas desaprovam que meninos e meninas façam música no mesmo ambiente (p.18). Essas movimentações e imersões sobre o tema, tanto no cenário nacional e internacional, revelam inúmeras possibilidades de pensar a religiosidade como um atravessamento importante na (auto)formação musical.

\section{Metodologia}

Ao revisitar as próprias experiências através da pesquisa autobiográfica, professores e professoras podem apropriar-se de seus movimentos constitutivos, tornando-se agentes ativos e conscientes de sua profissionalização. É possível desenvolver as narrativas como dispositivos de formação e autoformação, as quais se tornam proposições para espaços de experimentação de si, de conhecimento e autoconhecimento (OLIVEIRA, 2006). Desta feita, as narrativas se tornam espaço não de revelação de sentidos da docência, mas de construção de sentidos e significados que permitem a realização de uma manutenção de suas estruturas e seus modos de serem professores e músicos, no caso da presente pesquisa. Formando, através da observação e reflexão, novos constructos que permitem reforçar, reavaliar e reformular as relações no contexto em que está inserido.

Nesse sentido, o diário de pesquisa surge como uma opção de estudos sobre os processos com os quais o professor e/ou músico atribui sentido às práticas pedagógicomusicais e pedagógicas que realiza (BARBOSA; HESS 2010). Mais especificamente, sobre as práticas pedagógicas, autores como Zabalza (1994) destacam os diários de aula como ferramentas para a reflexão dos professores. Neste contexto, ganha relevância o conceito de dilema trazido por Zabalza (1994) e entendido como "todo o conjunto de situações bipolares ou multipolares que se apresentam ao professor no desenrolar de sua actividade profissional" (p.61).

\section{Análise de dados}

Os três alunos ${ }^{3}$ que produziram os dados analisados nesta comunicação descrevem os grupos de música em ambientes religiosos, sendo dois evangélicos ${ }^{4}$ e um católico ${ }^{5}$ :

\footnotetext{
${ }^{3}$ Os diários foram escritos pelos seguintes alunos do curso de Música da UFSM: Laura Cordeiro (Bolsista de Iniciação Científica CNPq), Maryanna Girão Bernardo (Bolsista de Iniciação Científica da FAPERGS) e João Domingos Sant'Anna (Bolsista de Iniciação Científica do FIPE/UFSM).

${ }^{4}$ Ministério de Louvor da Igreja em Cachoeira, na cidade de Cachoeira do Sul/RS, e Coral Jovem da Assembleia de Deus, na cidade de Santa Maria/RS.

${ }^{5}$ Ministério de Música do Grupo de Oração Jovem São Pedro da Catedral Católica, na cidade de Santa Maria/RS.
} 
O Ministério de Louvor da Igreja em Cachoeira é formado por membros da própria igreja. Não é um grupo grande, hoje atuam quatro integrantes fixos e mais três ministros eventualmente. O grupo se reúne uma vez por semana para ensaiar, toca nos dois cultos de celebração da igreja, no final de semana e em qualquer programação da igreja em que for solicitado. O nível de envolvimento com a música é bastante diferenciado no grupo, alguns estão apenas começando, outros já têm maior propriedade na área, fazem parte do ministério e tocam há mais tempo. Os dados da pesquisa emergiram no ano de dois mil e quinze, o primeiro diário foi escrito em março e o último em novembro. Ao total foram escritos oito diários, pela líder do Ministério e aluna do curso de licenciatura em música (Laura, diário de pesquisa).

O coral de jovens da Assembleia de Deus é formado por aproximadamente cinquenta componentes que vão se renovando a cada mudança de faixa etária, quando estes passam a ser considerados jovens pela igreja e quando deixam de assim o ser. O ensaio é feito uma vez por semana, no sábado à tarde, $\mathrm{e}$ periodicamente o coral cumpre escalas de acordo com a agenda da igreja e algumas vezes são convidados a cantar em outras igrejas filiais. A maioria dos jovens tem um prazer muito grande em participar do coral, porém alguns apresentam dificuldades técnicas que acabam atrapalhando o grupo como um todo no que se refere à afinação. No entanto, a igreja possui um grande comprometimento técnico/musical pelo fato de que muitos dos membros da igreja cursam, são formados, ou são doutores em música, e isso nos transmite tranquilidade em trabalhar coisas relacionadas a essa área. Os diários desta pesquisa foram escritos no período entre março a novembro de dois mil e quinze, totalizando oito diários (Maryanna, diário de pesquisa).

O ministério de música do grupo de oração jovem São Pedro, pertencente ao movimento da Igreja Católica, não tinha uma "formação fixa". Por vezes éramos 4 músicos e em outras ocasiões 6 músicos. Com violões, contrabaixo, vozes, teclado e bateria. O ministério, por não ser de uma "formação fixa" se reunia sempre antes de cada reunião de oração ou retiro para ensaiar e combinar o que seria executado. Salvo o aluno que produziu os dados e que servia em tal ministério, nenhum dos outros integrantes possuía uma instrução acadêmica de música, e todos os termos e resoluções musicais empregadas eram provenientes da experiência de cada um com a música. Sempre da maneira mais prática e acessível para se executar em um menor prazo de tempo visto que os ensaios eram sempre muito próximos a uma ocasião onde o ministério necessitava atuar (João, diário de pesquisa).

Zabalza (2004) propõe cinco etapas para a análise dos diários: 1) Construir a impressão geral dos diários; (fazer uma leitura completa), 2) Analisar os padrões e as repetições; 3) Identificar os pontos temáticos que vão aparecendo e fazer uma leitura transversal: 4) Analisar qualitativamente os elementos explícitos e implícitos da informação do diário e 5) Identificar os dilemas profissionais e pessoais que aparecem no diário. Após essas etapas, na transversalização dos diários dos três ambientes religiosos propostos, surgiram duas categorias principais derivadas de um grande dilema: "Ser músico ou ser ministro de louvor?". Para analisar os diferentes aspectos desse dilema, emergiram duas grandes categorias derivadas dos valores que estão no horizonte de significados (Souza, 2013) da música para os alunos e os músicos por eles liderados: Amar a Deus mais do que a música e Amar o próximo mais do que a música. Considerando como informante para refletir sobre o horizonte de significado a passagem Bíblica: 
Mestre, qual é o maior mandamento da Lei? Respondeu Jesus:" 'Ame o Senhor, o seu Deus de todo o seu coração, de toda a sua alma e de todo o seu entendimento'. Este é o primeiro e maior mandamento. E o segundo é semelhante a ele: 'Ame o seu próximo como a si mesmo'6.

Esses mandamentos informam a maneira como a música é praticada nesses ambientes, não em uma relação dicotômica entre ser músico ou ministro de louvor, mas em uma priorização das vivências religiosas e comunitárias sobre o fazer musical. Desta forma, no presente texto, destacamos trechos dos diários nos quais estão presentes este dilema principal e estas duas categorias, focalizadas na busca de respostas ao primeiro objetivo específico do projeto de pesquisa: "Compreender os transbordamentos de experiências do mundo vivido para as formações iniciais e continuadas de músicos e professores".

\title{
4.1 Amar a Deus mais do que a música
}

João, ao chegar atrasado ao ensaio depois de série de contratempos, conta como faz sacrifícios, pois considera que ministra a sua música para Deus:

\begin{abstract}
Cheguei todo molhado e com os pés molhados. E Não estava nem um pouco contente com minha situação. Porém foi o momento de lembrar que não era pra mim que eu tocava, mas para Deus, servindo a Ele no meu ministério mesmo com sofrimento, e doando minha musicalidade para que os outros jovens do grupo se encontrem com Deus nos momentos que estão lá no grupo (João, diário de pesquisa).
\end{abstract}

Já o episódio narrado por Maryanna demonstra como o envolvimento emocional com a religião se manifesta, nesse contexto, mais importante do que o fazer musical em si.

\begin{abstract}
Eu me vi diante de mais de cem jovens, todos com olhos atentos a mim, esperando o meu comando. (...) O repertório escolhido era muito lindo e enquanto os jovens cantavam pude ver a emoção através do semblante deles, muitos começaram a chorar e se entregar a aquele momento. Foi difícil também me conter. Como não me entregar também a um momento tão sublime mas que requer tanto da minha atenção? Será que estou sendo fria por não me envolver com aquele clima? Ou se me envolvesse, toda a apresentação iria desandar? (...) Optei por me concentrar no que estava fazendo mas fui profundamente tocada, em sentir a "presença de Deus" ali e em ver tantos jovens chorando, se entregando. Esses são um dos imprevistos que surgem, por exemplo, a metade dos jovens que choravam, por vezes não cantavam e acabavam não prestando atenção em mim, por estarem de olhos fechados. Mas apesar disso, foi incrível! Muito lindo e emocionante! É indescritível
\end{abstract}

\footnotetext{
${ }^{6}$ Mateus 22:36-39 in: Bíblia Sagrada. Traduzida em português por João Ferreira de Almeida. Revista e Atualizada no Brasil, 2.ed, Barueri/SP:Sociedade Bíblica do Brasil, 2008, 1664 p.
}

Revista Digital do LAV - Santa Maria - vol. 10, n. 2, p. 200 - 212 - mai./ago. 2017 ISSN 1983 - 7348 
essas experiências que estou tendo. Fui construindo todo o meu conhecimento musical na universidade, e ainda estou construindo. Toda a teoria que eu aprendi e aprendo está vindo junto com a prática, então para mim, é tudo inédito, novo. Sei que estou aprendendo muito (Maryanna, diário de pesquisa).

Para Laura, um conflito semelhante emerge ao refletir sobre o dilema entre duas 'personalidades', do músico e do adorador:

Desde que comecei a escrever os diários sobre o ministério de louvor (...) percebi claramente duas fortes "personalidades" do músico de igreja, aquele que foca mais na parte musical, técnica e questões musicais e aquele que foca na parte espiritual e é sensível ao que o momento está pedindo. Essas duas preocupações estão contidas no músico que é ministro de louvor, mas às vezes uma é mais forte que a outra, para alguns a parte técnica é mais importante e para outros a parte espiritual. Haverá casos em que essas duas personalidades vão divergir (Laura, diário de pesquisa).

João descreve a alegria dos jovens e os desafios dos músicos ainda dentro de um dilema entre se entregar a um clima de oração ou permanecer alerta como "um instrumento que toca um instrumento" (João, diário de pesquisa) nas mãos de Deus.

\begin{abstract}
Começamos o grupo com a música tema do retiro, e foi uma grande alegria ver os jovens sorrindo cantando aquela música e ver a animação de todos. Quando começou o momento de louvor um dos rapazes que estava conduzindo falou que nós íamos mudar a música, que seria outra, que já estávamos acostumados a tocar. Mas o tecladista nunca havia tocado aquela música, então ele pegou a cifra na internet pelo ipad e conseguimos tocá-la perfeitamente. O pregador pediu para tocarmos mais uma música no momento final do grupo, e o tecladista fez a mesma coisa, pegou a cifras na internet e conseguimos tocar sem dificuldades, pois já tocávamos ela a algum tempo. Ele demonstrava segurança quando falávamos que íamos trocar a música, demonstrava que estava preparado para isso (João, diário de pesquisa).
\end{abstract}

\title{
4.2 Amar o próximo mais do que a música
}

Por que amar os irmãos mais do que a música? Porque nestes ambientes, como em muitas outras circunstâncias de ensino musical, não existe a opção de "descartar" as pessoas que tem dificuldades de afinação, por exemplo, mas sim buscar soluções para incluí-las. As soluções encontradas fazem parte das reflexões dos diários, conforme narra Maryanna:

Por um acaso, a jovem senhora, a que desafinava, se posicionou justo na frente do microfone. As meninas que estavam na frente estavam bastante inquietas, foi quando uma delas me chamou. E eu sem saber para onde olhar, até que fui ao encontro de uma que me chamava, ela disse: "Aquela irmã tá bem na frente do microfone e ela desafina demais!". Eu fiquei mais nervosa ainda, como eu ia fazer

Revista Digital do LAV - Santa Maria - vol. 10, n. 2, p. 200 - 212 - mai./ago. 2017 ISSN 1983 - 7348 http://dx.doi.org/10.5902/1983734827859 
para tirar a senhora da frente do microfone? Foi quando uma das meninas me ajudou e pediu para trocar de lugar com ela, e apesar do constrangimento, tudo foi resolvido. Cantamos o repertório novo, e se havia alguém desafinando, não ecoou nos alto-falantes (Maryanna, diário de pesquisa).

Assim, dar a volta nessas "saias juntas" também ensina a ser professor de música. Outro aprendizado que aparece nos diários permite constatar que os alunos aprendem entre si e se motivam a partir de amizade mútua. A capacidade de observar leva a um aprendizado nem sempre centrado no professor, bem como exemplifica o quanto o amor recíproco e a camaradagem, muitas vezes, se tornam mais importantes que o fazer musical, de acordo com o comentário de Laura:

\begin{abstract}
Neste final de semana, realizei um almoço para o grupo de louvor dos adolescentes da igreja. (...) Acredito que essas atividades à parte refletem na hora de tocar junto, pois gera maior afinidade entre os membros do grupo e esse clima agradável de amizade, respeito e compreensão. (...) enquanto preparava a comida, eles se divertiam com brincadeiras e dinâmicas de grupo, depois que todos comeram eles tocaram juntos. Por enquanto eles só têm duas músicas ensaiadas, eu particularmente já enjoei das duas de tanto ouvir, porque já faz algumas semanas que eles estão ensaiando só essas, mas ao contrário de mim eles estavam muito empolgados tocando e repetindo, falando sobre o que poderia melhorar. Nesse momento em que olhei para eles tão focados percebi que minha presença ali era quase desnecessária e isso me deixou muito feliz (Laura, diário de pesquisa).
\end{abstract}

Além disso, a pessoa do músico enquanto "irmão de oração" é mais valorizada do que a sua própria música, como está refletido num dos diários de João:

\begin{abstract}
Acabei chegando no grupo com vinte minutos de atraso, já havia começado. O salão estava lotado novamente, uma animação que contagiava logo ao passar pela porta. Um dos irmãos de ministério estava conduzindo o grupo e tocando violão ao mesmo tempo. Minha expressão era de decepção por não ter conseguido chegar para poder tocar no grupo. Sentia-me como um soldado desarmado em uma guerra. E logo comecei a imaginar o quanto os meus irmãos de ministério ficariam chateados e desapontados comigo. Fiquei sentado no fundo do salão meio escondido, pois estava muito envergonhado pelo atraso. Logo veio o coordenador do grupo de oração, me dar um abraço e dizer: "Que bom que tu estás aqui", eu logo fui pedindo desculpas pelo atraso e ele me interrompeu dizendo: "O importante é que tu está aqui". Estas palavras me consolaram e eu pude entender o verdadeiro sentido da comunidade dentro do grupo de oração (João, diário de pesquisa).
\end{abstract}

\title{
5. Considerações
}

A utilização da abordagem (auto)biográfica na Iniciação Científicas de alunos em formação inicial nos cursos de música ainda é pouco explorada. Por outro lado, a partir da pesquisa relatada neste artigo, observa-se um crescente envolvimento de alunos de 
Iniciação Científica que procuram relacionar suas pesquisas com suas práticas cotidianas. Não obstante, percebeu-se também por parte deles uma não priorização de seu tempo para a pesquisa e um investimento pouco acentuado nos processos de reflexão de leitura e escrita envolvidos. Apesar disso, é possível serem localizadas diversas aprendizagens no processo espelhadas nos seus diários de pesquisa.

Laura parece refletir sobre os aspectos de socialização da música. Assim para o ministro de louvor a música não é só técnica e musicalidade, mas está a serviço do culto. Este aprendizado embora focalizado no ambiente religioso é igualmente verdadeiro para outras circunstâncias de ensino de música nas quais as relações humanas são tão importantes quanto as sonoridades. Além disso, a socialização, especialmente entre adolescentes, leva esta professora em formação a refletir sobre a alegria de poder deixar que os jovens músicos interajam entre si. Este parece ser um aprendizado importante se pensarmos numa abordagem de Educação Musical que não se centralize no professor, ou líder de grupo musical, mas aposte no aprendizado mútuo entre os membros.

No episódio em que os coralistas se emocionam e fecham os olhos, Maryanna não está "aprendendo muito" apenas sobre religião, mas também sobre música, sobre se emocionar e manter o controle, sobre continuar sendo a referência quando todos se entregam às emoções. Tais aprendizados podem transbordar para outros ambientes em que ela venha a ser professora de música. Escrever os diários a ajuda a pensar que "toda a teoria que aprendi e aprendo está vindo com a prática" (Maryanna, diário de pesquisa). Numa direção semelhante, lidar com as "saias justas" de admitir pessoas com dificuldades de afinação possibilita a ela um aprendizado muito interessante no que tange a uma postura em Educação Musical que busca incluir mais que excluir.

Por sua vez, João aprende capacidades de improvisar. Improvisar diante de seus atrasos na chuva e improvisar musicalmente. Novamente a técnica e a perfeição não são as metas, mas um serviço à religiosidade na qual acredita. Ele aprende para a sua prática de professor de música que às vezes a perfeição técnica não é o objetivo principal. Situações análogas podem acontecer, por exemplo, quando algumas pessoas procuram aulas de instrumento por motivos de lazer e não de profissionalização.

Todos os três alunos experienciaram a prática de narrar-se a partir dos diários de pesquisa e o quanto se tornou possível dar-se conta dos aprendizados em suas práticas musicais religiosas através dessa metodologia de pesquisa.

Nesta direção, a presente pesquisa pretende contribuir para a busca da compreensão dos horizontes de significado dos alunos de música em formação inicial, auxiliando, por conseguinte, à reflexão sobre currículos. Por outro lado, além de contribuir para os debates no ensino superior, pesquisas com este teor permitem compreender como a música é vivida e ensinada em um dos ambientes nos quais ela se torna de grande 
significado para as pessoas envolvidas. Principiar a ser pesquisador a partir do que é significativo para si é um princípio baseado na perspectiva (auto)biográfica. Para esses alunos, tal princípio se materializou em narrar sobre música e religião, pois para eles Deus é hierarquicamente superior à música. Estudando tais significados, permite aos alunos dar-se conta de seus aprendizados enquanto professores de música. Assim, esperamos que a presente pesquisa venha a fomentar os debates sobre pesquisa (auto)biográfica, especialmente com diários de pesquisa, estudos sobre ambientes religiosos cristãos e formação de professores, a partir da reflexão sobre vivências significativas em suas vidas.

\section{Referências}

BARBOSA, J.; HESS, R. O diário de pesquisa: o estudante universitário e seu processo formativo. Brasilia: Liberlivro, 2010.

BLAZINA, F. M. O ensino e a aprendizagem musical na Igreja Evangélica Assembléia de Deus em Porto Alegre. Especialização em Pedagogia da Arte. Universidade Federal do Rio Grande do Sul. Porto Alegre, 2013.

BRASIL. Ministério da Educação. Conselho Nacional de Educação. Conselho Pleno. Parecer no 9, de 8 de maio de 2001. Diretrizes Curriculares Nacionais para a Formação de Professores da Educação Básica, em nível superior, curso de licenciatura, de graduação plena. Brasília, 2001.

CATTELAN, L. Diários de um músico e professor: experiências na Catedral Metropolitana de Santa Maria - RS. Monografia (graduação em licenciatura em música) Universidade Federal de Santa Maria, Santa Maria, 2012.

KRAEMER, R. D. Dimensões e funções do conhecimento pedagógico-musical. Trad. Jusamara Souza. Revista Em Pauta v.11, n 16/17, abr/nov. p. 51-72. Porto Alegre, 2000.

LORENZETTI, M. A. G. A Igreja Católica como espaço de educação musical: aulas de canto em um grupo de jovens. In: XXI Congresso Nacional da Associação Brasileira de Educação Musical, 2013, Pirenópolis. Anais... Abem: Pirenópolis, 2013, p.199-208

LORENZETTI, M. A. G. Aprender e ensinar música na Igreja Católica: um estudo de caso em Porto Alegre/RS. Dissertação de Mestrado, PPGMUS/UFRGS, 2015

LOURO, A. L.; SOUZA, J. V. (Org.). Educação musical, cotidiano e ensino superior. Porto Alegre: Tomo Editorial, 2013, v. 1.

LOURO, A. L.; RECK, A. M.; OLIVEIRA, F. A.; ZACARIAS, L. F. G. Olhando para aprendizagens informais em música: algumas experiências junto a movimentos da Igreja Católica. In: XIV ENCONTRO REGIONAL SUL DA ABEM, 2011, Maringá. Anais... Abem: Maringá, 2011. p. 215-224.

MARQueS, E. F. L. Discurso e Prática Pedagógica na Formação de Alunos de Licenciatura em Música, em Salvador, Bahia, 1998. Dissertação (Mestrado em Música) - PPG Música, Universidade Federal da Bahia, Salvador, 1999. 
NOGUEIRA, A. G. A. T. Práticas de canto em grupo em uma comunidade religiosa em Anápolis. Monografia (licenciatura em música a distância) - Universidade de Brasília, Brasília, 2012.

NOVO, J. A. D. D. Educação musical do espaço religioso: um estudo sobre a formação musical na Primeira Igreja Presbiteriana de João Pessoa - Paraíba. Dissertação (mestrado), UFPB, 2015

OLIVEIRA, M. D. V. D. A formação musical dos professores de música da IBC Bagé. Trabalho de Conclusão de Curso (graduação) - Universidade Federal do Pampa, UNIPAMPA, 2016.

OLIVEIRA, V. Narrativas e saberes docentes. In: OLIVEIRA, Valeska (Org.). Narrativas e saberes docentes. Ijuí: Editora Unijuí, 2006. p.67-91.

RECK, A. M.; LOURO, A. L. A construção de identidades musicais em contextos religiosos: a cultura gospel. In: XXI Congresso Nacional da Associação Brasileira de Educação Musical, 2013, Pirenópolis. Anais... Abem: Pirenópolis, 2013 p.49-60

RECK, A. M.; LOURO, A. L.; RAPÔSO, M. Práticas de educação musical em contextos religiosos: narrativas de licenciandos a partir de diários de aula. Revista da ABEM, v. 22, p. 121-136, 2014.

SETTON, M. G. As religiões como agentes de socialização. Cadernos SERU, serie 2 vol.19, n. 2, dezembro de 2008.

SOARES, P. R. S.; KAISER, I. S. A música gospel: um olhar sobre a prática musical das igrejas evangélicas brasileiras nas últimas duas décadas. In: XXI Congresso Nacional da Associação Brasileira de Educação Musical, 2013, Pirenópolis. Anais... Abem: Pirenópolis, 2013, p.284-294

SOUZA, J. V. (org.) Aprender e ensinar música no cotidiano. 3. ed. Porto Alegre: Sulina, 2016. v. 1. 297p

SOUZA, J. V. Música, cotidiano e educação. Porto Alegre: PPG de música da UFRGS, 2000.

SOUZA, J. V. Cotidiano, sociologia e educação musical: experiências no ensino superior de música. In: LOURO, Ana Lúcia; SOUZA, Jusamara. (Org.). Educação musical, cotidiano e ensino superior. Porto Alegre: Tomo Editorial, 2013, v. 1, p.12-29

SOUZA, P. G.; LIMA, A. J. L. A formação em Música na IEARDERN Templo Central. In: XXI Congresso Nacional da ABEM, 2013, Pirenópolis-GO, Anais... Abem:Pirenópolis, 2013

TORRES, M. C. A. R. Entrelaçamentos de lembranças musicais e religiosidade: "quando soube que cantar era rezar duas vezes...". Revista da ABEM. Porto Alegre, v. 11, 6368 , set. 2004.

TRAVASSOS, E. Redesenhando as fronteiras do gosto: estudantes de música e diversidade musical. Horizontes Antropológicos. Porto Alegre, ano 5, n. 11, p. 119144, outubro de 1999.

ZABALZA, M. Diários de aula: contributo para o estudo dos dilemas práticos dos professores. Porto: Porto Editora, 1994. 
ZANANDREA, R. A. O canto e a música no contexto ritual da liturgia na igreja católica: desafios para a formação de agentes na diocese de Vacaria/RS. São Leopoldo: EST, 2009. Dissertação (Mestrado). Programa de Pós Graduação Teologia Prática, Escola Superior de Teologia. São Leopoldo, 2009.

\footnotetext{
' Possui graduação em Bacharelado em Música pela Universidade Federal do Rio Grande do Sul (1991), mestrado em Música pela Universidade Federal do Rio Grande do Sul (1995) e doutorado em Música pela Universidade Federal do Rio Grande do Sul (2004). Atualmente é professor associado da Universidade Federal de Santa Maria. Tem experiência na área de Artes, com ênfase em Educação Musical, atuando principalmente nos seguintes temas: narrativas de si, educação musical, formação de professores, identidades profissionais e cursos superiores de música. É membro das associações ISME, ABEM, ANPPOM, ANPED, BIOGraph.
}

ii Doutorando em Educação pela Universidade Federal de Santa Maria (PPGE/UFSM), com ênfase nos seguintes temas: identidades musicais, diversidade cultural, música e cotidiano e aprendizagens musicais. Foi professor assistente no curso de Música- Licenciatura da Universidade Estadual do Rio Grande do Sul - UERGS (2011-2013) e professor substituto no curso de Licenciatura em Música da Universidade Federal de Santa Maria - UFSM (2013-2014). É professor efetivo no curso de licenciatura em Música da Universidade Federal do Pampa (UNIPAMPA).

Enviado em: 26 de junho de 2017.

Aprovado em: 16 de agosto de 2017. 